\title{
Chronic Active Parietal Osteomyelitis Due to Salmonella typhi in a Patient with Sickle Cell Anemia
}

\section{Orak Hücreli Anemi Hastasında Salmonella typhi Kaynaklı Kronik Aktif Parietal Osteomiyelit}

\author{
Ahmad Antar ${ }^{1}$, George Karam², Maurice Kfoury ${ }^{3}$, Nadim El-Majzoub ${ }^{4}$ \\ ${ }^{1}$ Almoosa Specialist Hospital, Department of Internal Medicine, Division of Hematology-Oncology, Al-Ahsa, Saudi Arabia \\ ${ }^{2}$ Almoosa Specialist Hospital, Department of Neurosurgery, Al-Ahsa, Saudi Arabia \\ ${ }^{3}$ Almoosa Specialist Hospital, Department of Diagnostic Radiology, Al-Ahsa, Saudi Arabia \\ ${ }^{4}$ American University of Beirut Medical Center, Department of Pathology and Laboratory Medicine, Beirut, Lebanon
}

\section{To the Editor,}

Sickle cell disease (SCD) is a genetic disorder characterized by marked heterogeneity in clinical and hematologic severity, with musculoskeletal system manifestations being a major cause of morbidity and disability [1]. The increased susceptibility of SCD patients to infections, including osteomyelitis, has long been recognized with several mechanisms postulated including impaired splenic function, defects in complement activation, genetic factors, deficiencies in micronutrients, and the presence of infarcted or necrotic bone [2]. Salmonella is the most common cause of osteomyelitis in SCD, followed by Staphylococcus aureus and gram-negative enteric bacilli; this prevalence could be related to the fact that intravascular sickling of the bowel leads to patchy ischemic infarction [3,4]. The most common sites of osteomyelitis are the femur, tibia, or humerus. Patients usually present with acute onset of pain, swelling, and tenderness over the affected area in association with fever and elevated inflammatory markers. However, in some cases, osteomyelitis has atypical presentations with a more indolent course and often with abscess formation [5]. Here we present a 50-year-old female patient with sickle cell anemia (SCA) who developed parietal osteomyelitis with abscess formation and involvement of the dura due to Salmonella typhi, who was treated successfully by surgery followed by antibiotics.

A 50-year-old Saudi female patient living in the Eastern Province of Saudi Arabia, diagnosed with SCA ( $\mathrm{HgS}$ : 78\%) with occasional vaso-occlusive crisis and no sickle cell-related complications, presented to us with a 1-month history of a painless right parietal subgaleal collection increasing in size over time with no history of trauma and no fever or neurological manifestations. Laboratory testing revealed an elevated white blood cell count and a high estimated sedimentation rate level $(125 \mathrm{~mm} / \mathrm{h})$. Magnetic resonance imaging of the brain revealed an osteolytic defect centered on the right parietal bone and sizable subgaleal complex collection (Figure 1). The patient underwent right

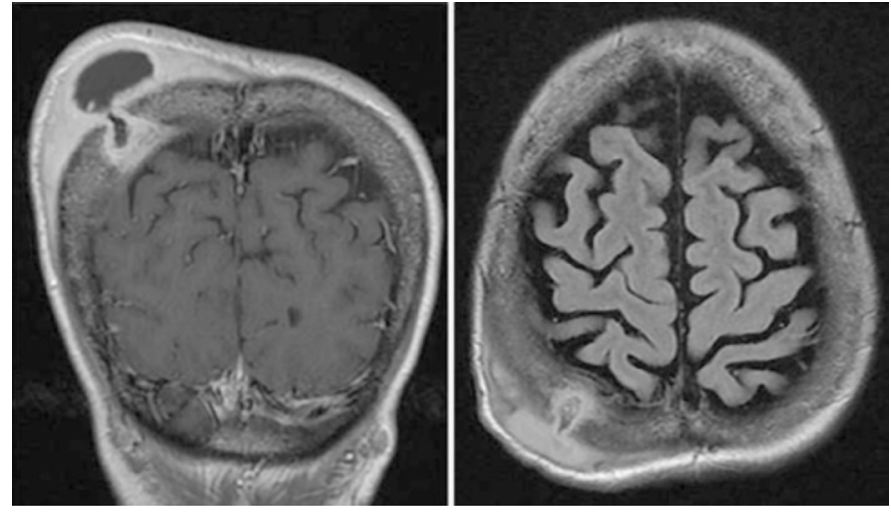

Figure 1. Magnetic resonance imaging of the brain demonstrating peripheral enhancement of the scalp abscess alongside noticeable enhancement of the adjacent soft tissues, pathological bone, and underlying pachymeningeal layer enhanced on a coronal T1W slice (left) with a clear intra-osseous edematous edema in keeping with osteomyelitic changes isolating a central bone sequestrum, communicating with a subperiosteal/subgaleal fluid collection on a fluid attenuated inversion recovery weighted slice (right).

parietal craniectomy with cranioplasty (removal of the right parietal subgaleal collection and the corresponding bone in addition to the invaded dura). Pathology of the specimen revealed a right parietal subgaleal abscess and right parietal bone chronic active osteomyelitis. Culture of the specimen grew Salmonella typhi.

The morbidity of chronic osteomyelitis combined with other complications of SCD decreases patients' quality of life. Patients with SCD are more prone to osteomyelitis. The most common causative organism is Salmonella. The usual manifestations of osteomyelitis are pain, swelling, tenderness, and fever. However, like in our case, sometimes osteomyelitis presents late, as a more indolent process often with abscess formation and in unusual and more critical sites. Our case highlights the atypical presentation of osteomyelitis in a patient with SCD, which could cause devastating complications if not treated properly, early, and by a multidisciplinary team approach. 
Keywords: Sickle cell anemia, Osteomyelitis, Salmonella typhi

Anahtar Sözcükler: Orak hücreli anemi, Osteomiyelit, Salmonella typhi

Conflict of Interest: The authors of this paper have no conflicts of interest, including specific financial interests, relationships, and/or affiliations relevant to the subject matter or materials included.

\section{References}

1. Almeida A, Roberts I. Bone involvement in sickle cell disease. Br J Haematol 2005;129:482-490.

2. Booth C, Inusa B, Obaro SK. Infection in sickle cell disease: a review. Int J Infect Dis 2010;14:e2-e12.

3. Atkins BL, Price EH, Tillyer L, Novelli V, Evans J. Salmonella osteomyelitis in sickle cell disease children in the East End of London. J Infect 1997;34:133-138.

4. Burnett MW, Bass JW, Cook BA. Etiology of osteomyelitis complicating sickle cell disease. Pediatrics 1998;101:296-297.

5. Barrett-Connor E. Bacterial infection and sickle cell anemia. An analysis of 250 infections in 166 patients and a review of the literature. Medicine (Baltimore) 1971;50:97-112.

\title{
Acquired Leukocyte Inclusion Bodies Resembling Döhle Bodies During Acute Cholangitis
}

\author{
Akut Kolanjit Seyrinde Lökositlerde Döhle Benzeri Edinsel İnklüzyonlar
}

\author{
Gökhan Özgür ${ }^{1}$, Musa Barış Aykan², Murat Yıldırım, Selim Sayın ${ }^{1}$, Ahmet Uygun ${ }^{3}$, Cengiz Beyan ${ }^{4}$ \\ ${ }^{1}$ Gülhane Training and Research Hospital, Department of Hematology, Ankara, Turkey \\ ${ }^{2}$ Health Sciences University, Gülhane Faculty of Medicine, Department of Internal Medicine, Ankara, Turkey \\ ${ }^{3}$ Health Sciences University, Gülhane Faculty of Medicine, Department of Gastroenterology, Ankara, Turkey \\ ${ }^{4}$ TOBB University of Economics and Technology Faculty of Medicine, Department of Internal Medicine, Ankara, Turkey
}

To the Editor,

A 66-year-old woman was admitted to the gastroenterology department with epigastric pain, nausea, and subicterus. Her complaints had begun $6 \mathrm{~h}$ earlier. Her abdomen was soft and flat, with localized tenderness on palpation in the right subcostal area. Laboratory studies revealed a white cell count of $17.9 \times 10^{9} / \mathrm{L}$, hemoglobin concentration of $14.4 \mathrm{~g} / \mathrm{dL}$, and platelet count of $48 \times 10^{9} / \mathrm{L}$, and they were notable for elevated serum cholestatic enzymes. The abdominal ultrasound was remarkable for cholangitis. The patient received broad-spectrum antibiotics. A peripheral blood smear examination, performed to evaluate thrombocytopenia, revealed the presence of blue intracytoplasmic inclusions in neutrophils (Figures 1A-C). On the $11^{\text {th }}$ day of treatment, her blood smear was examined once again and the Döhle body-like inclusions were resolved (Figure 1D).

May-Hegglin anomaly is an uncommon autosomal dominant abnormality characterized by large, basophilic inclusion bodies (resembling Döhle bodies) in neutrophils $[1,2]$. Döhle bodies

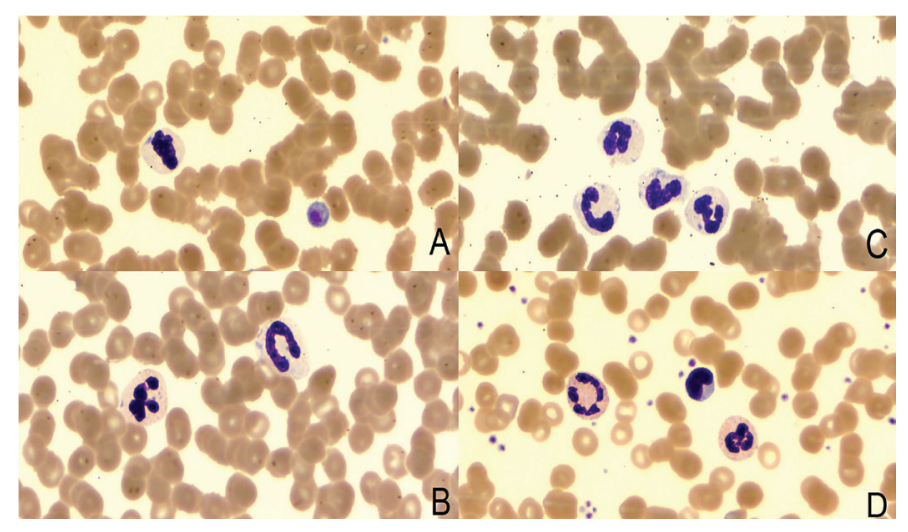

Figure 1. A) Inclusion bodies in neutrophils and macrothrombocyte; B), C) inclusion bodies in neutrophils; D) peripheral blood smear after treatment.

can be seen in bacterial infections. Hematologic findings of systemic diseases may be confused with hematological diseases such as May-Hegglin anomaly. We thought that the granules were Döhle bodies due to cholangitis. The disappearance of the inclusion bodies upon treatment is important in differential diagnosis. 